REVIEW ARTICLE

CURRENT CONCEPTS

\section{Enteropathogens and Chronic Illness in Returning Travelers}

\author{
Allen G.P. Ross, M.D., Ph.D., G. Richard Olds, M.D., Allan W. Cripps, Ph.D., \\ Jeremy J. Farrar, M.D., Ph.D., and Donald P. McManus, Ph.D., D.Sc.
}

\footnotetext{
res
}

N 2011, APPROXIMATELY 980 MILLION PEOPLE TRAVELED INTERNATIONALLY. ${ }^{1}$ More than 522 million people from developed countries traveled overseas; an estimated 50 million to 100 million people traveled to developing countries. ${ }^{1-4}$ In 2007, the U.S. Department of Commerce estimated that at least 30 million Americans traveled to developing regions. ${ }^{4}$ Approximately $8 \%$ of travelers to the developing world require medical care during or after travel, and more than a quarter of those who seek medical assistance present with gastrointestinal symptoms. ${ }^{5-7} \mathrm{Al}-$ though diarrhea occurs in up to $50 \%$ of people who travel to a developing country, it is only one of a number of infectious gastrointestinal illnesses that travelers may acquire. ${ }^{8-10}$ The broad spectrum of infectious gastrointestinal pathogens causing chronic illness in travelers, apart from travelers' diarrhea, ${ }^{7,11,12}$ has not been well characterized.

A recent study analyzed data from the GeoSentinel Surveillance Network (which consists of 42 specialized travel or tropical-medicine sites located around the world) on 25,867 returned travelers over a 9-year period (from 1996 to 2005).9 ${ }^{\text {The }}$ analysis was performed on data from travelers who sought medical attention and not on the overall rates of gastrointestinal illness acquired during travel. The data showed that microbiologically confirmed gastrointestinal disease was diagnosed in approximately 30\% (7442) of the travelers. Of the 2902 clinically significant pathogens that were isolated, approximately 65\% were parasitic, $31 \%$ bacterial, and 3\% viral. Six organisms (giardia, campylobacter, Entamoeba histolytica, shigella, strongyloides, and salmonella species) accounted for $70 \%$ of the gastrointestinal burden (Fig. 1). There were no diagnostic codes specifically for enterotoxigenic Escherichia coli, the most frequent cause of travelers' diarrhea, or other commonly described pathogens, such as enteroaggregative E. coli, aeromonas, or plesiomonas. ${ }^{9}$ Coccidian parasites such as cyclospora, cryptosporidium, microsporidia, and isospora are increasingly recognized as causes of travelers' diarrhea, but their percentages may have been underestimated in the GeoSentinel survey, since the diagnosis of these organisms requires specific staining techniques that are not routine in many laboratories. ${ }^{9}$ Similarly, viral pathogens, such as rotavirus and norovirus, are not routinely tested for at health centers, and their percentages could have been underestimated; however, these agents usually cause a short-term illness that typically resolves before travelers seek medical attention. ${ }^{9}$ The purpose of this review is to examine these enteropathogens that cause chronic and severe illness, as well as schistosoma (also known as the blood fluke, or bilharzia), which causes schistosomiasis, a common intravascular infection that is an increasingly recognized risk to travelers. ${ }^{13-15}$
From Griffith Health Institute, Griffith University, Gold Coast, QLD (A.G.P.R., A.W.C.), and the Division of Infectious Diseases, Queensland Institute of Medical Research, Brisbane (D.P.M.) - both in Australia; the School of Medicine, University of California Riverside, Riverside (G.R.O.); and Oxford University Clinical Research Unit, Ho Chi Minh City, Vietnam (J.J.F.). Address reprint requests to Dr. Ross at a.ross@griffith.edu.au.

N Engl J Med 2013;368:1817-25. DOI: 10.1056/NEJMra1207777 Copyright @ 2013 Massachusetts Medical Society. 


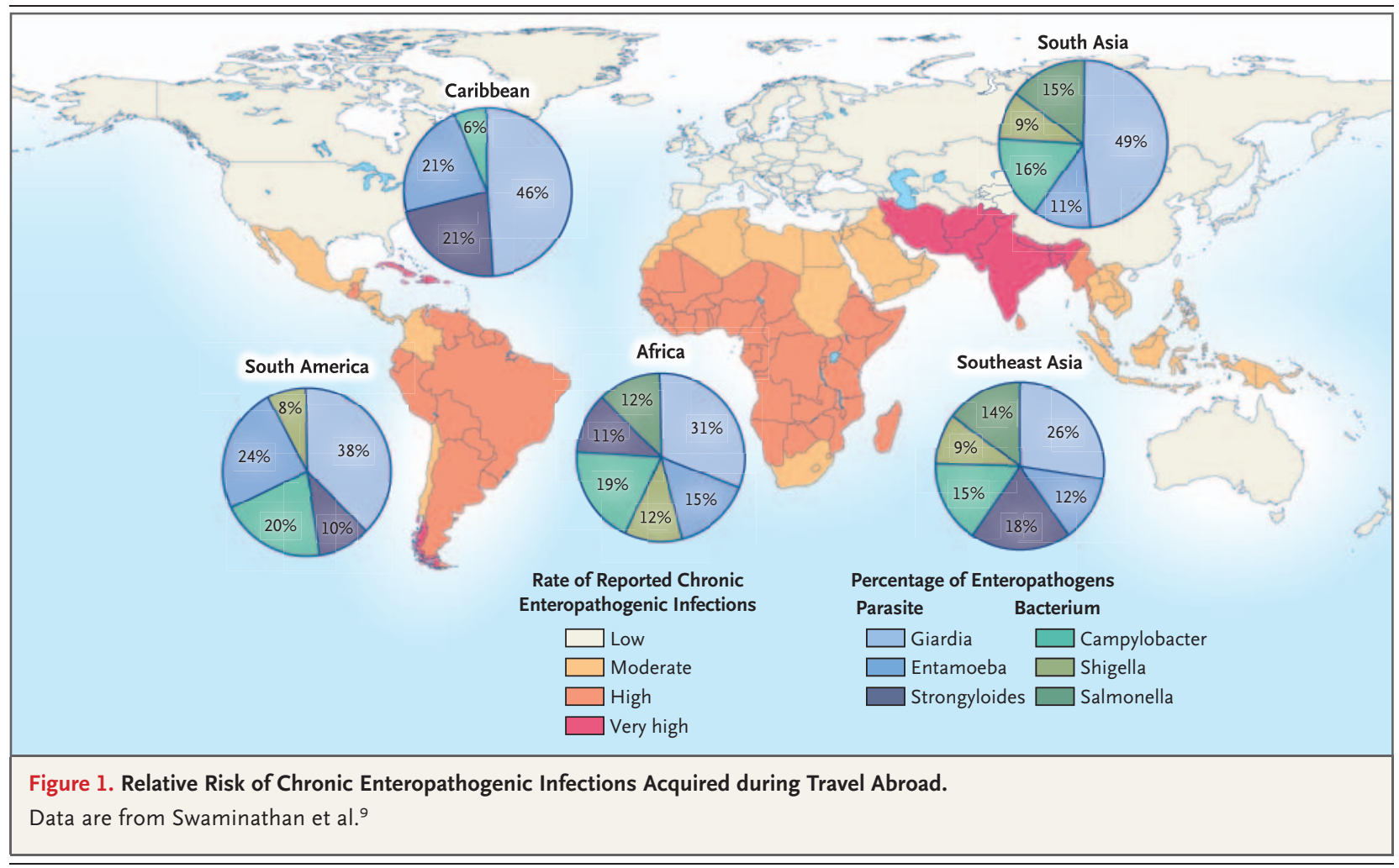

\section{ENTEROPATHOGENS}

Parasitic and bacterial enteropathogens cause severe and chronic gastrointestinal illness in the returning traveler. Table 1 lists the major enteropathogens.

\section{PARASITIC PATHOGENS}

Most reviews of gastrointestinal illness among travelers focus on pathogens associated with acute illness (with clinical symptoms appearing within 14 days after exposure), which are predominantly bacterial or viral in origin. Consequently, parasites such as giardia, entamoeba, strongyloides, and schistosoma are often neglected or insufficiently covered.

\section{Giardia}

Giardia lamblia (also called G. intestinalis or G. duodenalis) is highly contagious (ingestion of as few as 10 to 25 cysts may cause disease), with persons becoming infected through the ingestion of cysts in contaminated food or water. However, personto-person transmission is possible. ${ }^{16,17}$ The clinical manifestations range from mild intestinal problems that resolve spontaneously to complex symptoms that last up to several weeks, such as protein-losing enteropathy, postinfectious fatigue, chronic diarrhea, abdominal pain, nausea, and weight loss. ${ }^{18}$ There is now evidence that rotavirus may work synergistically with giardia to enhance pathogenesis through more successful attachment of the ventral disk of trophozoites to the infected epithelium. ${ }^{19}$ In children, the disease can cause growth and cognitive impairment as a result of iron and micronutrient deficiencies. ${ }^{16,18,20}$ The two developmental stages of giardia species are the mobile flagellate trophozoites, which are responsible for the clinical symptoms of the disease, and the cyst forms, the infective stage, in which trophozoites are surrounded by a rigid, protective cyst wall that allows the parasite to survive outside the host intestine. ${ }^{16,17}$ After exposure to the acid environment of the host's stomach, the cysts rupture, releasing fully developed trophozoites into the proximal small intestine, where replication and tissue damage occur. ${ }^{16}$ This close association between the trophozoites and the proximal small intestine results in pathophysiological processes that interfere with 


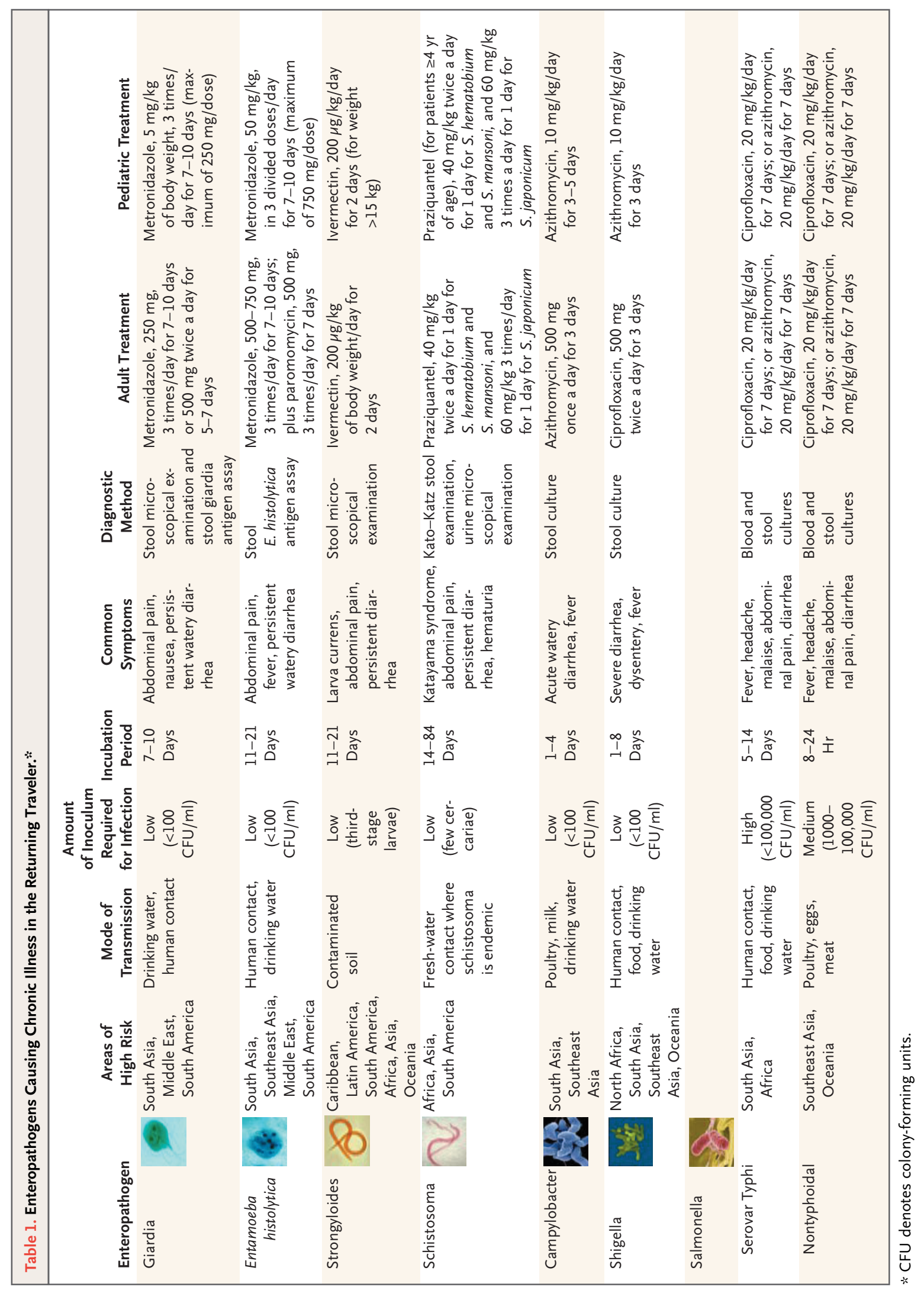


nutrient absorption and ultimately lead to villous atrophy, crypt hyperplasia, intestinal hyperpermeability, and damage to the brush border of the enterocyte. ${ }^{16,21,22}$ Host CD8+ T cells, excretorysecretory glycoproteins of the parasite, and proteases are involved in orchestrating this pathological response. ${ }^{16,22-24}$

\section{Entamoeba}

Three entamoeba species (E. histolytica, E. dispar, and E. moshkovskii) have been identified, but only E. histolytica and E. moshkouskii are pathogenic in humans, causing amebiasis. The parasite is acquired through the ingestion of food or water contaminated with fecal cysts. After it has been ingested, the cyst emerges in the terminal ileum as an active trophozoite, which migrates to the colon where it colonizes the mucus layer by binding to host mucin oligosaccharides with the ameba cell-surface adhesion molecule galactose and N-acetyl-D-galactosamine (Gal/GalNAc)-specific lectin. ${ }^{25}$ Invasion may take days to years after the initial infection and is characterized by fever, abdominal pain, and bloody dark-brown diarrhea. ${ }^{26}$ However, $90 \%$ of cases are asymptomatic and self-limiting. ${ }^{26}$ Symptomatic disease occurs when trophozoites invade the mucosa and submucosa by means of secretory enzymes, and some trophozoites enter the portal circulation and disperse to the liver and other soft organs. ${ }^{6,25}$ Disease of the right colon is common and is associated with the following serious complications: strictures, rectovaginal fistulas, bowel obstruction, toxic megacolon, perforation, peritonitis, and death. ${ }^{26}$ Only $1 \%$ of clinical cases of amebiasis involve the liver. ${ }^{26}$ The right lobe of the liver is four times as likely to be involved as is the left lobe. ${ }^{26}$ Hepatic invasion results in tissue destruction and the formation of microabscesses that gradually coalesce. ${ }^{6,26}$ Amebic ulcers of the penis are rare but can resemble squamous-cell carcinoma, chancroid, primary syphilis, or granuloma inguinale. ${ }^{27}$ Amebic cervicitis mimicking a posterior-wall fibroid has been recently reported. ${ }^{28}$

\section{Strongyloides}

There are more than 50 species of strongyloides, the parasitic helminth roundworm, with Strongyloides stercoralis (threadworm) being the most dominant in humans. ${ }^{29}$ Third-stage filariform larvae penetrate the skin (usually the foot) of the human host, reach the lungs by way of the blood circulation, and enter respiratory pathways. From there, they migrate upward through the trachea, are swallowed, and finally reach the small intestine, where they mature into adult egg-laying female worms. ${ }^{29,30}$ Female worms embed in the submucosa of the duodenum, where they produce dozens of eggs per day. These hatch in the gut lumen, and the first-stage rhabditiform larvae either are passed out in the feces and develop into infective third-stage larvae or remain in the gastrointestinal tract of the human host and start a new infection cycle (autoinfection). ${ }^{29}$

Autoinfection can result in persistent infection for decades. ${ }^{30}$ More than $50 \%$ of patients with a chronic infection are asymptomatic. ${ }^{27}$ This is due to partial immunity, which has been shown to be correlated with eosinophilia, humoral IgM and IgG levels, and HLA-DRB1 ${ }^{\star} 0901$ haplotype. ${ }^{31}$ For some patients with disease, the symptoms include erythematous pruritus, skin eruptions, larva currens, abdominal pain, diarrhea, and weight loss. ${ }^{29,32}$ In travelers presenting with eosinophilia or elevated IgE levels, strongyloides should be considered in the differential diagnosis. Susceptibility in male patients has been shown to be related to IgG4 antibodies and resistance to albendazole treatment. ${ }^{31}$ In immunocompromised persons, strongyloidiasis can cause a hyperinfection syndrome owing to the reproductive capacity of the parasite inside the host. ${ }^{30}$ In cases of dissemination disease, the hyperinfection syndrome can be associated with a mortality rate close to $90 \%$.

\section{Schistosoma}

Schistosomiasis is a common chronic helminth disease caused by intravascular parasitic schistosoma trematode worms. The three most important species in humans are Schistosoma hematobium, S. mansoni, and S. japonicum. ${ }^{33,34}$ Schistosome transmission requires the contamination of water by egg-containing feces or urine, a specific freshwater snail as intermediate host, and human contact with water inhabited by the intermediate host snails. Schistosome larvae (cercariae) emerge from the snails and penetrate human skin, thereby instigating infection. ${ }^{33-35}$ A maculopapular eruption consisting of discrete erythematous, raised lesions that vary in size from 1 to $3 \mathrm{~cm}$ may arise at the site of percutaneous penetration by the cercariae. Patients with acute schistosomiasis, or the Katayama syndrome, which usually 
begins with the deposition of schistosome eggs into host tissues, can present with fever, malaise, myalgia, fatigue, nonproductive cough, diarrhea (with or without blood), hematuria (S. hematobium), and right-upper-quadrant pain. Schistosomiasis is an increasingly recognized risk to travelers, particularly adventure tourists. ${ }^{13-15}$ A skin reaction may develop within a few hours after cercarial penetration in migrants or tourists infected for the first time, although a rash may appear as much as a week later. In cases of infection with S. mansoni and S. japonicum, a T-cell-mediated granulomatous reaction to schistosome eggs leads to fibrosis and chronic disease of the human liver, resulting in the development of severe hepatosplenic schistosomiasis; in cases of S. hematobium, this reaction leads to fibrosis and calcification of the bladder and ureters, which can result in bladder cancer. ${ }^{33-35}$

\section{BACTERIAL PATHOGENS}

\section{Campylobacter}

Campylobacter species are a leading cause of acute infectious diarrhea in the industrialized world. They are increasingly being recognized as pathogens in resource-poor countries. ${ }^{12}$ Campylobacter jejuni and $C$. coli are the main species causing foodborne illness. ${ }^{36}$ Campylobacteriosis is transmitted by the fecal-oral route, with foodborne transmission accounting for approximately $80 \%$ of cases. ${ }^{7}$ The consumption of raw meat and undercooked poultry substantially increases the risk of infection. The majority of cases of $C$. jejuni are self-limiting and do not require antibiotic treatment. ${ }^{37}$ Common symptoms of severe infection include abdominal pain, acute watery diarrhea, fever, and occasionally dysentery. A rapid increase in resistance to fluoroquinolones by $C$. jejuni may be associated with postinfectious irritable bowel syndrome. ${ }^{37}$ Guillain-Barré syndrome, acute transverse myelitis, myocarditis, and reactive arthritis may also develop as a result of intestinal infection with C. jejuni. ${ }^{7,32} C$. jejuni enters the intestinal mucosa basolaterally through $\mathrm{M}$ cells with the help of a microtubule-based entry system. ${ }^{6,38}$ Infection spreads to adjacent cells through hostinvasion receptors that are sequestered basolaterally. ${ }^{6,38}$ The type IV secretion system mediates invasion into host cells. ${ }^{39}$ Cytolethal distending toxin, a nuclease, results in the arrest of the cell cycle and in DNA damage. ${ }^{6,39,40} \mathrm{C}$. jejuni biofilms have been observed on primary human ileal tissue, and these may enhance survival and transmission. ${ }^{41}$ Orally residing campylobacter species can form biofilms on tooth pockets and epithelialassociated plaques that may contribute to periodontitis. ${ }^{41}$

\section{Salmonella}

Salmonella are enteric bacteria causing typhoid fever, paratyphoid fever, non-typhi salmonella infections, and foodborne illness. Salmonella serovar Typhi, which has no animal reservoir, is spread from person to person, and paratyphi are major pathogens that cause enteric fever in the developing world. ${ }^{42}$ Nontyphoidal salmonella, including Salmonella enterica, are the major cause of food poisoning globally. ${ }^{42}$ Patients infected with S. enterica typically present with acute watery diarrhea, fever, and abdominal pain. However, in Africa, patients may present with a sepsislike syndrome including fever, hepatosplenomegaly, and respiratory symptoms, without enterocolitis. ${ }^{43}$ Ninety-five percent of cases of S. enterica infection are caused by food (e.g., contaminated chicken, eggs, or peanut butter). ${ }^{7}$ Salmonella has been implicated in the early pathogenesis of inflammatory bowel disease, but the large studies undertaken have yet to find a definitive association. ${ }^{44,45}$ S. enterica invades the intestinal epithelium and survives within macrophages with the help of two type III secretion systems (T3SS) encoded by salmonella pathogenicity island 1 (T3SS SPI-1) and 2 (T3SS SPI-2), respectively. ${ }^{6,46}$ SPI-1 and SPI-2 encode needlelike complexes that can inject bacterial effector proteins directly into host cells and ultimately take over cell function - such as that associated with cytoskeletal architecture, membrane trafficking, signal transduction, and cytokine gene expression - resulting in bacterial intracellular survival and colonization. ${ }^{47,48}$ After invasion of host cells, salmonella localize within salmonella-containing vacuoles and establish a niche where they survive and replicate. ${ }^{48}$

\section{Shigella}

Four species of shigella (Shigella dysenteriae, S. flexneri, S. sonnei, and S. boydii) are known to be pathogenic in humans. Shigella has no natural reservoir but is highly contagious and spreads from person to person or through the ingestion of contaminated food. ${ }^{49}$ As few as 200 colony-forming units per milliliter are required for infectious in- 
oculation. ${ }^{7,49}$ Common symptoms of shigellosis are bright-red bloody diarrhea, fever, abdominal pain, and dysentery. The organism invades the intestinal epithelial cells of the colon through $M$ cells from the basolateral side and spreads laterally. ${ }^{6}$ Shigella is similar to salmonella in that it possesses a large plasmid that encodes the principal T3SS and other virulence factors for invasion. ${ }^{6,50}$ The pathogenic mechanism of shigellosis is complex, involving Shiga toxins (enterotoxin, cytotoxin, and neurotoxin), cytokine-mediated inflammation of the colon, and necrosis of the colonic epithelium. ${ }^{50}$ The resulting colitis and ulceration of the mucosa results in bloody (bright red) mucoid stools, febrile diarrhea, or both. ${ }^{50}$

\section{DIAGNOSIS}

\section{HISTORY AND PHYSICAL EXAMINATION}

In the assessment of the returning traveler, a detailed travel history and physical examination are essential.711,32 Disease patterns vary greatly among countries, and there can also be differences within countries, depending on environment, ecology, altitude, climate, vectors, and other factors. ${ }^{11}$ Other useful information to obtain from the patient includes exposure to insect bites, exposure to ill people, type of food and liquids consumed, vaccination history, and medications taken. A physician should also know the incubation periods of potential infections. Acute clinical symptoms (appearing < 14 days after exposure) could be indicative of enteric viral or bacterial infections, whereas chronic symptoms (appearing $\geq 14$ days after exposure) may suggest an enteric protozoan or helminthic infection. Consideration of these factors, in combination with careful assessment of the timing of clinical signs and symptoms, should help the physician determine the appropriate laboratory test to order and whether empirical treatment should be initiated. ${ }^{32}$

\section{LABORATORY TESTINC}

Laboratory diagnosis of a specific pathogenic strain, virulence factor, or toxin is required so that antimicrobial treatment can be targeted against the causative organism. Routine blood tests should consist of a full blood count (e.g., leukocytes, eosinophils, neutrophils, and lymphocytes), liver-function tests, and a basic metabolic panel. A stool sample should be obtained, cultured, and examined for bacteria, cysts, eggs, and parasite larvae. ${ }^{4}$ When parasites (giardia, strongyloides, or schistosoma) are included in the differential diagnosis, microscopical examination of the stool or specialized laboratory tests will be required. Light microscopy has traditionally been used to view eggs and other parasite stages in the diagnosis of intestinal parasites. Although microscopy can be performed cheaply, its sensitivity depends on the intensity of infection, the freshness of the specimen, and the experience of the microscopist. ${ }^{4}$ Certain agars allow for culture of specific pathogens, such as salmonella, shigella, and campylobacter. ${ }^{4}$

\section{OTHER DIAGNOSTIC METHODS}

Several stool antigen assays specific for E. histolytica are commercially available (e.g., from Techlab in the United States and Cellabs in Australia) to make an accurate diagnosis of intestinal or hepatic amebiasis on the basis of the Gal/ GalNAc-specific lectin. ${ }^{26,32,51}$ Microscopical examination of the stool is no longer performed for amebiasis or strongyloides because of its low sensitivity ( 25 to $60 \%$ ) and specificity (10 to $50 \%)^{27}$; with microscopy, it is easy to confuse E. histolytica with the identically appearing and much more common nonpathogenic parasite E. dispar. ${ }^{26}$ Antigen-detection assays with immunofluorescence are now commonly used in the diagnosis of giardia and strongyloides, given the difficulties in morphologic identification of the parasites. ${ }^{16}$ The use of strongyloides-specific antigen (NIE) has improved the specificity of enzyme-linked immunosorbent assays (ELISAs), which are routinely used in laboratories in North America. Polymerasechain-reaction analysis can detect most parasitic infections and is more sensitive than antibody detection, but it is not performed routinely in pathology clinics. ${ }^{34,52,53}$ Oligonucleotide microarray analysis performed on DNA is now being explored for potential use in the detection and genotyping of campylobacter species. ${ }^{54}$ In patients with bloody diarrhea, stool cultures and fecal toxin assays by means of a commercial ELISA are recommended. ${ }^{7}$ Upper gastrointestinal endoscopy is useful in the investigation of patients with persistent diarrhea. Changes in villous morphologic features can be confirmed by duodenal biopsy, which may also reveal the presence of protozoal cysts or trophozoites, but biopsy is rarely performed because of advances in antigen-detection techniques. Duodenal fluid can be aspirated 
during a biopsy for the detection of giardia cysts and trophozoites and for the larvae of strongyloides. ${ }^{32}$ Ultrasonography and MRI studies may also be helpful in determining the degree of hepatic involvement in patients infected with entamoeba or schistosoma species.

\section{TREATM E N T}

\section{ANTIDIARRHEAL AGENTS}

An oral rehydration solution (e.g., Pedialyte) should be administered in patients with recent weight loss, prolonged skinfold (decreased skin turgor), dry oral mucosa, sunken eyes, altered mental status, vomiting and diarrhea, and marked dehydration and electrolyte loss. For patients with more severe diarrhea, isotonic intravenous fluids (e.g., lactated Ringer's solution) should be administered. In infants, breast-feeding should be maintained, along with an oral rehydration solution plus a zinc supplement. A diet of easily digestible food (soups, toast, crackers, mashed potatoes, rice, and bananas) is often recommended for those with acute watery diarrhea. ${ }^{7}$ Antimotility drugs such as loperamide and diphenoxylate are useful in reducing the symptoms of watery diarrhea but should not be administered without antibacterial therapy in patients presenting with fever, dysentery, or both. ${ }^{7}$ These pharmaceutical agents are not recommended for children and young infants owing to the potential for central nervous system effects and the possibility of respiratory depression. ${ }^{32}$ Chemoprophylactic use of the nonabsorbable agent bismuth subsalicylate (Pepto-Bismol) reduces diarrhea rates by 40 to $65 \%{ }^{4}$

\section{ANTIMICROBIAL AGENTS}

For campylobacter and shigella, antimicrobial therapy is indicated (Table 1). For nontyphoid salmonella diarrhea, the objective of therapy is to treat or prevent the occurrence of bacteremic disease. ${ }^{44}$ Antibiotics are given to patients in whom bacteremic disease is suspected. ${ }^{44}$ For schistosomiasis, the highly effective drug praziquantel $60 \mathrm{mg}$ per kilogram of body weight in three doses in 1 day for S. japonicum, and $40 \mathrm{mg}$ per kilogram in two doses in 1 day for S. mansoni and S. hematobium - remains the treatment of choice. ${ }^{33,34}$ Many travelers self-medicate for acute diarrhea. If the diarrhea persists, the organism could have become resistant to the antibiotics or it could have been misdiagnosed and could in fact be a parasite.

Drug resistance in enteropathogens has become a major global problem. Multidrug-resistant Salmonella enterica Typhi and S. enterica Paratyphi are common in Asia and sub-Saharan Africa, and there are increasing reports of reduced susceptibility to fluoroquinolones. C. jejuni resistance to fluoroquinolones has become a concern in Southeast Asia, with rates of resistance of $80 \%$ reported from Thailand. ${ }^{41}$ This resistance may be due in part to a Thr86Ile mutation in GyrA, which modulates DNA supercoiling homeostasis. ${ }^{55}$ Multidrug resistance in a distinct genotype of S. enterica serovar Typhimurium (ST313) has emerged in Africa, and to date we know of no intervention studies about the best antimicrobial regimen to treat acute infection and prevent relapse. ${ }^{43}$

Knowledge of global resistance patterns can help inform the choice of empirical antibiotics in returning travelers. Glucocorticoids are contraindicated in immunosuppressed persons who are infected with strongyloides. A short course (6 to 17 days) of treatment with glucocorticoids in immunocompromised persons has been associated with the hyperinfection syndrome and death. ${ }^{56}$

FUTURE DIRECTIONS

The world's population is growing exponentially. Most of this growth is occurring in the developing world, where it appears unlikely that food hygiene and personal hygiene will improve in the foreseeable future. As international travel to developing countries increases, physicians specializing in travel and infectious diseases, as well as general practitioners, will have to become more knowledgeable about travel-related illnesses, including sexually transmitted infections, in order to better inform travelers of the health risks in the country of their destination. Physicians need to equip travelers with appropriate vaccinations, malaria chemoprophylaxis, and effective antibacterial drugs for self-treatment should the traveler become ill with a bacterial enteropathogen.

Further assessment of the use of prophylactic drugs and the development of vaccines to protect against travel-related diseases may occur. Rifaximin could be used prophylactically against most bacterial pathogens. ${ }^{12}$ However, the drug does not have efficacy against campylobacter or para- 
sitic infections. ${ }^{57}$ Recent evidence suggests that nitazoxanide may have potential as an empirical treatment for pediatric infectious diarrhea. ${ }^{58} \mathrm{~A}$ high-throughput drug screening for E. histolytica identified auranofin (a drug approved by the Food and Drug Administration for rheumatoid arthritis) as an active agent against E. histolytica in culture that is 10 times more potent than metronidazole. 59

The following three vaccines against typhoid fever are licensed in the United States: a live, attenuated strain Ty21a vaccine, a parenteral Vi capsular polysaccharide vaccine, and a parenteral killed whole-cell vaccine. ${ }^{60} \mathrm{New}$ vaccines for other major enteropathogens are under development. Promising candidates include Vi-conjugate Salm. enterica Typhi vaccine; G. lamblia $\alpha 1$-giardinbased live heterologous vaccine ${ }^{61} ;$ E. histolytica
Eh29-CT $\times$ B fusion protein oral vaccine ${ }^{62}$; Shig. flexneria $2 a$ conjugate vaccine ${ }^{63}$; Shig. sonnei virG (iscA) live attenuated vaccine ${ }^{64} ;$ C. jejuni capsular polysaccharide conjugate vaccine ${ }^{34}$; Schis. mansoni tetraspanin recombinant vaccine, SmTSP-265; and a Schis. japonicum plasmid-based DNA transmission-blocking vaccine, SjCTPI-Hsp70.66 A new database for diarrheal pathogens, dbDiarrhea, has been developed that may greatly enhance future vaccine development. ${ }^{67}$ The database can be freely accessed at www.juit.ac.in/attachments/ dbdiarrhea/diarrhea_home.html.

Dr. Cripps reports receiving through his institution consulting fees from Probiotec, grant support from Danisco and GlaxoSmithKline, and travel support from GlaxoSmithKline and holding stock in Bioxyne. He also has a pending patent application through Danisco regarding probiotics. No other potential conflict of interest relevant to this article was reported.

Disclosure forms provided by the authors are available with the full text of this article at NEJM.org.
REFERENCES

1. United Nations. UNWTO tourism highlights. 2012 edition (http://dtxtq4w60xqpw .cloudfront.net/sites/all/files/docpdf/ unwtohighlights12enlr_1.pdf).

2. Cartwright R. Gastrointestinal illness in tourists: whose responsibility? Euro Surveill 2004;9(3):5.

3. Gorbach SL. How to hit the runs for fifty million travelers at risk. Ann Intern Med 2005;142:861-2.

4. Pawlowski SW, Warren CA, Guerrant $\mathrm{R}$. Diagnosis and treatment of acute and persistent diarrhea. Gastroenterology 2009; 136:1874-86.

5. Freedman DO, Weld LH, Kozarsky PE, et al. Spectrum of disease and relation to place of exposure among ill returned travelers. N Engl J Med 2006;354:119-30. [Erratum, N Engl J Med 2006;355:967.]

6. Navaneethan U, Giannella RA. Infectious colitis. Curr Opin Gastroenterol 2011;27:66-71.

7. DuPont HL. Bacterial diarrhea. N Engl J Med 2009;361:1560-9.

8. Hill DR. The burden of illness in international travelers. N Engl J Med 2006; 354:115-7.

9. Swaminathan A, Torresi J, Schlagenhauf $\mathrm{P}$, et al. A global study of pathogens and host risk factors associated with infectious gastrointestinal disease in returned international travellers. J Infect 2009;59:19-27.

10. Shah N, DuPont HL, Ramsey DJ. Global etiology of travelers' diarrhea: systematic review from 1973 to the present. Am J Trop Med Hyg 2009;80:609-14.

11. Thielman NM, Guerrant RL. Acute infectious diarrhea. N Engl J Med 2004; 350:38-47.

12. DuPont HL. What's new in enteric in- fectious diseases at home and abroad? Curr Opin Infect Dis 2005;18:407-12.

13. Ansart S, Perez L, Vergelt O, Danis M. Illness in travelers returning from the tropics: a prospective study of $622 \mathrm{pa}$ tients. J Travel Med 2005;12:312-8.

14. Nicolls DJ, Weld LH, Schwartz E, et al. Characteristics of schistosomiasis in travelers reported to the GeoSentinel Surveillance Network 1997-2008. Am J Trop Med Hyg 2008;79:729-34.

15. Marano C, Freedman DO. Global health surveillance and travelers' health. Curr Opin Infect Dis 2009;22:423-9.

16. Andersen MD, Neumann NF. Giardia intestinalis: new insights on an old pathogen. Med Microbiol 2007;18:35-42.

17. Carranza PG, Lujan HD. New insights regarding the biology of Giardia lamblia Microbes Infect 2010;12:71-80.

18. Jerlström-Hulqvist J, Ankarklev J, Svärd SG. Is human giardiasis caused by two different Giardia species? Gut Microbes 2010;1:379-82

19. Bhavnani D, Goldstick JE, Cevallos W, Trueba G, Eisenberg JNS. Synergistic effects between rotavirus and coinfecting pathogens on diarrheal disease: evidence from a community-based study in Northeastern Ecuador. Am J Epidemiol 2012; 176:387-95.

20. Ankarklev J, Jerlström-Hulqvist J, Ringqvist E, Troell K, Svärd SG. Behind the smile: cell biology and disease mechanism of Giardia species. Nat Rev Microbiol 2010;8:413-22.

21. Cotton JA, Beatty JK, Buret AG. Host parasite interactions and pathophysiology in Giardia infections. Int J Parasitol 2011; 41:925-33.

22. Buret AG, Mitchell K, Muench DG,
Scott KG. Giardia lamblia disrupts tight junctional ZO-1 and increases permeability in nontransformed human small intestinal epithelial monolayers: effects of epidermal growth factor. Parasitology 2002; 125:11-9.

23. Scott KG, Yu LC, Buret AG. Role of CD8+ and CD4+ T lymphocytes in jejunal mucosal injury during murine giardiasis. Infect Immun 2004;72:3536-42.

24. Solaymani-Mohammadi S, Singer SM. Giardia duodenalis: the double-edge sword of immune responses to giardiasis. Exp Parasitol 2010;126:292-7.

25. Mortimer L, Chadee K. The immunopathogenesis of Entamoeba histolytica. Exp Parasitol 2010;126:366-80.

26. Pritt BS, Clark CG. Amebiasis. Mayo Clin Proc 2008;83:1154-9.

27. Hung CC, Chang SY, Ji DD. Entamoeba histolytica infection in men who have sex with men. Lancet Infect Dis 2012;12: 729-36.

28. Mukherjee S, Nagarsenkar A, Chandra S, Sahasrabhojanee M, Sawant D. Ameobic cervicitis mimicking posterior wall fibroid: a rare presentation. J Micro Immunol Infect 2012 June 26 (Epub ahead of print).

29. Olsen A, van Lieshout L, Marti H, et al. Strongyloidiasis - the most neglected of the neglected tropical diseases? Trans R Soc Trop Med Hyg 2009;103:967-72.

30. Segarra-Newnham M. Manifestations, diagnosis and treatment of Strongyloides stercoralis infection. Ann Pharmacother 2007;41:1992-2001.

31. Iriemenam NC, Sanyaolu AO, Oyibo WA, Fagbenro-Beyioku AF. Strongyloides stercoralis and the immune response. Parasitol Int 2010;59:9-14. 
32. Casburn-Jones AC, Farthing MJG. Management of infectious diarrhoea. Gut 2004;53:296-305.

33. Gryseels B, Polman K, Clerinx J, Kestens L. Human schistosomiasis. Lancet 2006;368:1106-18.

34. Gray DJ, Ross AG, Li YS, McManus DP. Diagnosis and management of schistosomiasis. BMJ 2011;342:d2651.

35. Ross AGP, Vickers D, Olds GR, Shah SM, McManus DP. Katayama syndrome. Lancet Infect Dis 2007;7:218-24.

36. Schlenker C, Surawicz CM. Emerging infections of the gastrointestinal tract. Best Pract Res Clin Gastroenterol 2009;23: 89-99.

37. Kirkpatrick BD, Tribble DR. Update on human Campylobacter jejuni infections. Curr Opin Gastroenterol 2011;27:1-7.

38. van Putten JP, van Alphen LB, Wosten MM, de Zoete MR. Molecular mechanisms of Campylobacter infection. Curr Top Microbiol Immunol 2009;337:197-229.

39. $\mathrm{Hu} \mathrm{L}$, Tall BD, Curtis SK, Kopecko DJ. Enhanced microscopic definition of Campylobacter jejuni 81-176 adherence to, invasion of, translocation across, and exocytosis from polarized human intestinal Caco-2 cells. Infect Immun 2008;76: 5294-304.

40. Dasti JI, Tareen AM, Lugert R, et al. Campylobacter jejuni: a brief overview on pathogenicity-associated factors and disease-mediating mechanisms. Int J Med Microbiol 2010;300:205-11.

41. Man SM. The clinical importance of emerging Campylobacter species. Nat Rev Gastroenterol Hepatol 2011;8:669-85.

42. Gordon MA. Invasive non-typhoidal Salmonella disease - epidemiology, pathogenesis, and diagnosis. Curr Opin Infect Dis 2011;24:484-9.

43. Feasey NA, Dougan G, Kingsley RA, Heyderman RS, Gordon MA. Invasive nontyphoidal salmonella disease: an emerg ing and neglected tropical disease in Africa. Lancet 2012;379:2489-99.

44. DuPont HL. Approach to the patien with infectious colitis. Curr Opin Gastroenterol 2012;28:39-46.

45. Jess T, Simonsen J, Nielsen NM, et al. Enteric Salmonella or Campylobacter in fections and the risk of inflammatory bowel disease. Gut 2011;60:318-24.
46. Hapfelmeier S, Stecher B, Barthel M, et al. The Salmonella pathogenicity island (SPI)-2 and SPI-1 type III secretion systems allow Salmonella serovar typhimurium to trigger colitis via MyD88odependent and MyD88-independent mechanisms. J Immunol 2005;174:1675-85.

47. Dougan G, John V, Palmer S, Mastroeni P. Immunity to salmonellosis. Immunol Rev 2011;240:196-210.

48. Sánchez-Vargas FM, Abu-El-Haija MA, Gómez-Duarte OG. Salmonella infections: an update on epidemiology, management, and prevention. Travel Med Infect Dis 2011;9:263-77.

49. Musher DM, Musher BL. Contagious acute gastrointestinal infections. $\mathrm{N}$ Engl J Med 2004;351:2417-27.

50. Phalipon A, Sansonetti PJ. Shigellosis: innate mechanisms of inflammatory destruction of the intestinal epithelium, adaptive immune response, and vaccine development. Crit Rev Immunol 2003;23: 371-401.

51. Singh A, Houpt E, Petri WA. Rapid diagnosis of intestinal parasitic protozoa with a focus on Entamoeba histolytica. Interdiscip Perspect Infect Dis 2009;2009: 547090.

52. Parr JB, Sevilleja JE, Amidou S, et al. Detection and quantification of Cryptosporidium in HCT-8 cells and human fecal specimens using real-time polymerase chain reaction. Am J Trop Med Hyg 2007; 76:938-42.

53. ten Hove R, Schuurman T, Kooistra M, Mфller L, van Lieshout L, Verweij JJ. Detection of diarrhoea-causing protozoa in general practise patients in the Netherlands by multiplex real-time PCR. Clin Microbiol Infect 2007;13:1001-7.

54. Marotta F, Zilli K, Tonelli A, Sacchini $\mathrm{L}$, et al. Detection and genotyping of Campylobacter jejuni by use of DNA oligonucleotide arrays. Mol Biotechnol 2013; 53:182-8.

55. Han J, Wang Y, Sahin O, Shen Z, Guo B, Shen J. Zhang Q. A fluoroquinolone resistance associated mutation in gyrA affects DNA supercoiling in Campylobacter jejuni. Front Cell Infect Microbio 20122:21. 56. Mejia R, Nutman TB. Screening, prevention, and treatment for hyperinfection syndrome and disseminated infections caused by Strongyloides stercoralis. Curr Opin Infect Dis 2012;25:458-63.

57. Adachi JA, DuPont HL. Rifaxmin: a novel nonabsorbed rifamycin for gastrointestinal disorders. Clin Infect Dis 2006;42:541-7.

58. Rossignol JF, Lopez-Chegne N, Julcamoro LM, Carrion ME, Bardin MC. Nitazoxanide for the empiric treatment of pediatric infectious diarrhea. Trans $\mathrm{R}$ Soc Trop Med Hyg 2012;106:167-73.

59. Debnath A, Parsonage D, Andrade RM, et al. A high-throughput drug screen for Entamoeba histolytica indentifies a new lead and target. Nat Med 2012;18:956-60. 60. Pasetti MF, Simon JK, Sztein MB, Levine MM. Immunology of gut mucosal vaccines. Immunol Rev 2011;239:125-48. 61. Jenikova G, Hruz P, Andersson MK, et al. $\alpha 1$-Giardin based live heterologous vaccine protects against Giardia lamblia infection in a murine model. Vaccine 2011; 29:9529-37.

62. Carrero JC, Contreras-Rojas A, SánchezHernández B, et al. Protection against murine intestinal amoebiasis induced by oral immunization with the $29 \mathrm{kDa}$ antigen of Entamoeba histolytica and cholera toxin. Exp Parasitol 2010;126:359-65.

63. Kweon MN. Shigellosis: the current status of vaccine development. Curr Opin Infect Dis 2008;21:313-8.

64. Kosek M, Yori PP, Olortegui MP. Shigellosis update: advancing antibiotic resistance, investment empowered vaccine development, and green bananas. Curr Opin Infect Dis 2010;23:475-80.

65. Tran MH, Pearson MS, Bethony JM, et al. Tetraspanins on the surface of Schistosoma mansoni are protective antigens against schistosomiasis. Nat Med 2006; 12:835-40.

66. Da'dara AA, Li YS, Xiong T, et al. DNA-based vaccines protect against zoonotic schistosomiasis in water buffalo. Vaccine 2008;26:3617-25.

67. Ramana J, Tamanna. dbDiarrhea: the database of pathogen proteins and vaccine antigens from diarrheal pathogens. Infect Genet Evol 2012;12:1647-51.

Copyright (C) 2013 Massachusetts Medical Society.

RECEIVE THE JOURNAL'S TABLE OF CONTENTS EACH WEEK BY E-MAIL

To receive the table of contents of the Journal by e-mail every Wednesday evening, sign up at NEJM.org. 